\title{
Proptosis ocular: a propósito de un caso
}

Q. Foguet Boreu, G. Coll de Tuero

M édicos de Familia. CAP Anglès. Girona.

\section{Ocular proptosis: a case review}

\section{RESUMEN}

La protusión ocular o exoftalmos constituye un hallazgo relativamente poco frecuente en la prácti ca clínica diaria. Por su baja frecuencia y por la multiplicidad de etiologías causantes del mismo es un reto diagnóstico para el médico de familia.

Se presenta el caso de un varón de 71 años al que se le detecta una proptosis ocular derecha.

El estudio inicial de un exoftalmos comprende: anamnesis, exploración física y pruebas comple mentarias (ecografía orbitaria y de función tiroi dal).

En general, cuando nos encontremos con un exoftalmos bilateral tendremos que pensar en una disfunción tiroidea, mientras que si es unilateral, sospechar un tumor orbitario.

Palabras clave: Proptosis ocular. Exoftalmos. Metástasis orbitaria.

\section{ABSTRACT}

Ocular proptosis or exophthalmos is not a very commnon finding in the daily clinical practice. For its low frequency and for the multiplicity of etiolo gies it can be caused by, the ocular proptosis cons titute a challenge of diagnosis for the family doctor.

We report the case of a right ocular proptosis diagnosed in a 71 years old man.

The initial study of an exophtalmos requires an anamnesi, a physique exploration and complemen tary proof (orbital ecography and thyroidal func tion).

In general, when we find a bilateral exophthal mos we must think of a thyroidal disfunction whe reas if is it unilateral, we must suspect an orbital tumor.

Key words: Ocular proptosis. Exophthalmos. Orbital mestastasis.

\section{INTRODUCCIÓN}

La proptosis ocular o desplazamiento del globo ocular hacia adelante también conocido como exoftalmos es un hallazgo relativamente poco frecuente en la práctica clínica.

El abordaje de una proptosis aislada en Atención Primaria constituye un verdadero reto diagnóstico, tanto por la multiplicidad de etiologías causantes de proptosis ocular como por la accesibilidad mermada a pruebas complementarias desde este ámbito. Orientarlo, sin embargo, constitu- ye una tarea que el médico de familia no puede declinar.

En líneas generales, una buena anamnesis y exploración física podrá orientar al diagnóstico. De todas maneras, frente a una exoftalmía bilateral tenemos que pensar en una disfunción tiroidea, mientras que si es unilateral tenemos que sospechar un tumor orbitario ${ }^{1}$.

Presentamos un caso de proptosis ocular aislada, a la vez que introducimos una posible actitud diagnóstica frente a un exoftalmos. 


\section{CASO CLÍNICO}

Hombre de 71 años, agricultor de profesión. Fumador de puros ( 2 al día). Hábito enólico moderado (20-30 g/día). Con antecedentes patológicos de artropatía degenerativa crónica (cervical, lumbar y caderas; prótesis de cadera), hiperuricemia, hiperlipemia, hipotiroidismo en tratamiento con Levotiroxina, adenocarcinoma de próstata detectado 4 años antes con tratamiento con antiandrógenos (Flutamida) y con un análogo de la hormona liberadora de gonadotropinas (Leuprorelina depot mensual), hepatopatía crónica (esteatosis hepática), embolia de la rama de la arteria de la retina derecha de probable origen ateroembólico, bronquitis crónica obstructiva y herpes zóster.

Consulta por imposibilidad de cerrar el ojo izquierdo. Dos días antes había salido de cacería al amanecer. En la exploración destacaba un signo de Bell positivo a nivel del ojo izquierdo y se objetiva una lagoftalmía (imposibilidad de cerrar completamente el ojo izquierdo) por parálisis del orbicular. Paralelamente se observa una protusión ocular derecha con edema del párpado superior derecho. Se orienta como una parálisis facial periférica izquierda (a frigore) y un exoftalmos derecho a estudiar. Se pauta tratamiento corticoideo oral en dosis in descendo.

Un electromiograma realizado un mes después del tratamiento ratifica el diagnóstico de parálisis periférica izquierda y lo hace compatible con secuelas de una parálisis facial izquierda en vías de resolución espontánea. El enfermo recupera la movilidad del orbicular izquierdo.

Respecto al exoftalmos derecho, se pide una analítica general con pruebas tiroidales y anticuerpos antitiroidales. En el análisis resalta una glucemia de $128 \mathrm{mg} / \mathrm{dl}$, una gamma-glutamil transpeptidasa de 86,9 U/1 y una fosfatasa alcalina de 329 U/l. El volumen de sedimentación globular, la hormona estimulante del tiroides (TSH), los anticuerpos antitiroidales y el antígeno prostático específico (PSA) eran normales. Se solicita una ecografía orbitaria derecha la cual no muestra imágenes intra-retrooculares sospechosas, razón por la que se programa una tomografía axial computerizada (TAC).

Posteriormente, en el contexto de una reagudización de su patología respiratoria, se objetiva una hipofonesis, por lo que se realiza una radiografía de tórax en la que se halla un nódulo pulmonar. El paciente ingresa en el hospital de referencia para estudio de nódulo pulmonar y exoftalmos derecho.

En la TAC torácica se observa un nódulo de $2 \mathrm{~cm}$ en el lóbulo superior izquierdo. El estudio de extensión muestra en la radiología lumbar y de pelvis una imagen lítica en isquión derecho. En el TAC de cráneo se visualiza una doble lesión ósea blástica en el ala esfenoidal y a nivel fronto-parietal izquierdo compatibles con metástasis.

Valoran el caso en el servicio de oncología y concluyen que se trata de una neoplasia de próstata con metástasis óseas en progresión, con un nódulo pulmonar (probablemente neoplásico) no tributario de más estudios. Se decide retirar el tratamiento hormonal previo y se inicia tratamiento con Estramustina. El enfermo es derivado al servicio de cuidados paliativos y a nuestro centro para seguimiento.

\section{DISCUSIÓN}

La valoración clínica de una protusión ocular comprende, en primer lugar evaluar el exoftalmos. En condiciones normales el párpado superior esconde la parte superior de la córnea. El párpado inferior no pasa más allá del limbo, dejando entrever la conjuntiva. De perfil la protusión ocular es más aparente. Si bien el diagnóstico del exoftalmos es clínico, se puede objetivar con un exoftalmómetro (tipo Hertel) pero no es de uso habitual en la clínica.

La exploración física comprende evaluar la agudeza visual (AV), valorar la afectación corneal (tinción de fluoresceína), palpar la órbita (valorando si la protusión es reductible o no, si hay hipertonia o hipotonia ocular y si hay thrill), auscultar la órbita (soplo), comprobar la motilidad de los músculos oculares y valorar el área otorrinolaringológica (ORL) (rinoscopia anterior y transiluminación).

En cuanto a las pruebas complementarias, la ecografía orbitaria se sitúa, por su accesibilidad, como la primera técnica en Atención Primaria para el estudio de un exoftalmos. Si la ecografía no nos orienta sobre la etiología causante de la enfermedad, la tomografía axial computeritzada (TAC) y, en último término la resonancia magnética nuclear son las pruebas a escoger. Este orden de petición se puede modificar según la sospecha diagnóstica (Tabla I).

De forma paralela, se determinaran los parámetros biológicos siguientes: triyodotironina (T3), tiroxina (T4), TSH y anticuerpos antiotiroidales que serán de gran utilidad para descartar una disfunción tiroidal.

Con respecto a nuestro caso, atribuíamos las metástasis orbitarias a la neoplasia de próstata por el hecho que el carcinoma de próstata produce de forma típica metastasis osteoblásticas, mientras que en el supuesto que el nódulo pulmonar fuera maligno, las metástasis hubieran sido, con toda probabilidad, osteolíticas. Por otro lado, sabíamos que las metástasis óseas son la forma más frecuente de extensión del cáncer de próstata. Sin embargo, los lugares donde metastatiza con más frecuencia son la 
Tabla I

\section{GRANDES SÍNDROMES ETIOPATOGÉNICOS DE EXOFTALMOS ${ }^{1}$}

\begin{tabular}{|c|c|c|c|c|c|}
\hline Síndromes & Tipo & $\begin{array}{l}\text { Subtipos y } \\
\text { signos clínicos }\end{array}$ & Diagnóstico & Evolución & Tratamiento \\
\hline Distiroidismos & $\begin{array}{l}\text { Bilateral }(80 \%) \\
\text { Unilateral }\end{array}$ & $\begin{array}{l}\text { Edema conjuntival } \\
\text { Hipertrofia glándula lacrimal } \\
\text { Edema pupilar } \\
\text { Dolor o malestar a la presión } \\
\text { ocular } \\
\text { Fatiga ocular } \\
\text { Otros: Retracción palpebral } \\
\text { superior } \\
\text { Diplopia } \\
\text { Déficit visual } \\
\text { Afectación corneal }\end{array}$ & $\begin{array}{l}\text { Ecografía, TAC } \\
\text { Hipertitoidismo } \\
\text { (aumento T3 libre, } \\
\text { T4 libre, disminución TSH) } \\
\text { Enfermedad Basedow (bocio, } \\
\text { exoftalmos, taquicardia, } \\
\text { problemas nerviosos } \\
\text { y gastrointestinales) } \\
\text { Tíroiditis de Hashimoto } \\
\text { Hipotiroidismo } \\
\text { Eutiroidismo (Sde. Saint-Yves) } \\
\text { Exoftalmia edematosa maligna* }\end{array}$ & $\begin{array}{l}\text { Aumenta, se } \\
\text { estabiliza y } \\
\text { disminuye } \\
\text { en } 3 \text { meses } \\
\text { a } 3 \text { años }\end{array}$ & $\begin{array}{l}\text { Antitiorideos de } \\
\text { síntesis, } \\
\text { Yodo 131, } \\
\text { tiroidectomía } \\
\text { Fase inflamatoria: } \\
\text { Corticoides } \\
\text { Radioterapia (RTP) } \\
\text { Descompresión } \\
\text { orbitaria }\end{array}$ \\
\hline \multirow[t]{6}{*}{ Tumorales } & \multirow[t]{6}{*}{$\begin{array}{l}\text { Unilateral } \\
\text { de hormona } \\
\text { liberadora de } \\
\text { la hormona } \\
\text { luteinizante }\end{array}$} & $\begin{array}{l}\text { Sdes. Limfoproliferativos } \\
\text { Lenta, irreductible, aislada } \\
\text { AV raramente alterada }\end{array}$ & Pruebas radiológicas. Biopsia & $\begin{array}{l}\text { Bajo } \\
\text { Intermedio } \\
\text { Según tipos } \\
\text { células }\end{array}$ & $\begin{array}{l}\text { RTP y/ o } \\
\text { Quimioterapia } \\
\text { (QTP) }\end{array}$ \\
\hline & & $\begin{array}{l}\text { T. glándula lacrimal } \\
\text { Indolora, progresiva, sin } \\
\text { afectación oculomotores, } \\
\text { desplazando el ojo hacia abajo }\end{array}$ & Pruebas radiológicas & & $\begin{array}{l}\text { Exéresis total } \\
\text { sin rotura } \\
\text { de la cápsula }\end{array}$ \\
\hline & & $\begin{array}{l}\text { T. propagados } \\
\text { Tumores sinusales (mucoceles) } \\
\text { Tumores malignos (raramente) } \\
\text { (maxilar o etmoides) } \\
\text { Exoftalmia tardía, dolor ocular } \\
\text { mal sistematizado, pérdida AV, } \\
\text { diplopia, epífora, ptosis }\end{array}$ & Pruebas radiológicas & & \\
\hline & & $\begin{array}{l}\text { T. metastásicos } \\
\text { Cáncer mama } 42 \% \text { de casos } \\
\text { (mujer) } \\
\text { Carcinoma broncopulmonar. } \\
\text { Prostático, melamoma y riñón } \\
\text { Exoftalmos importante, doloroso, } \\
\text { quemosis y déficit oculomotor }\end{array}$ & Pruebas radiológicas & & RTP y QTP \\
\hline & & $\begin{array}{l}\text { T. neurógenos } \\
\text { Meningioma nervio óptico } \\
\text { Meningioma esfenoorbitario } \\
\text { propagado } \\
\text { Exoftalmia lentamente } \\
\text { progresiva, lateralizada } \\
\text { (a veces), déficits oculomotores } \\
\text { y disminución AV }\end{array}$ & Pruebas radiológicas & & Cirugía \\
\hline & & $\begin{array}{l}\text { Otros tumores orbitarios (raros) } \\
\text { Osteoma de seno frontal } 0 \\
\text { etmoidal, histiocitosis. }\end{array}$ & & & \\
\hline Inflamatorias & Unilateral & $\begin{array}{l}\text { No específicas } \\
\text { Miositis, dacrioadenitis, } \\
\text { forma anterior, apical y difusa }\end{array}$ & $\begin{array}{l}\text { Pruebas radiológicas } \\
\text { Biopsia (infiltración } \\
\text { polimorfa células } \\
\text { inflamatorias) }\end{array}$ & $\begin{array}{l}\text { Aguda } 0 \\
\text { subaguda }\end{array}$ & Corticoides \\
\hline
\end{tabular}


Tabla I

GRANDES SÍNDROMES ETIOPATOGÉNICOS DE EXOFTALMOS ${ }^{1}$ (continuación)

\begin{tabular}{|c|c|c|c|c|c|}
\hline Síndromes & Tipo & $\begin{array}{l}\text { Subtipos y } \\
\text { signos clínicos }\end{array}$ & Diagnóstico & Evolución & Tratamiento \\
\hline & & $\begin{array}{l}\text { Específicas } \\
\text { Celulitis orbitaria } \\
\text { Bacteriana } \\
\text { Dolorosa, aparición brutal, } \\
\text { quemosi, edema cálido y rojo } \\
\text { de párpado, fiebre } \\
\text { Otras: micótica -mucormicosis } \\
\text { rinoorbitaria, aspergilosis, } \\
\text { tuberculosis, sífilis, parásitos }\end{array}$ & $\begin{array}{l}\text { Examen ORL } \\
\text { (pus a nivel } \\
\text { meato medio) } \\
\text { Radiología senos } \\
\text { paranasales } \\
\text { Siempre descartar } \\
\text { Tromboflebitis del } \\
\text { seno cavernoso } \\
\text { (aumento del calibre } \\
\text { de la vena oftálmica } \\
\text { superior de manera } \\
\text { bilateral, alargamiento } \\
\text { de los músculos } \\
\text { oculomotores y del seno } \\
\text { cavernoso con una } \\
\text { imagen eventual de } \\
\text { infarto de la arteria } \\
\text { cerebral) }\end{array}$ & & $\begin{array}{l}\text { Antibióticos } \\
\text { de amplio } \\
\text { espectro }\end{array}$ \\
\hline Traumáticas & Unilateral & $\begin{array}{l}\text { Hematoma orbitario, enfisema } \\
\text { orbitario, celulitis orbitaria } \\
\text { postfractura } \\
\text { Pueden ser pulsátiles por una } \\
\text { comunicación carotídea- } \\
\text { cavernosa o cerrebro-orbitaria. }\end{array}$ & Pruebas radiológicas & & \\
\hline \multirow[t]{2}{*}{ Vasculares } & \multirow[t]{2}{*}{ Unilateral } & $\begin{array}{l}\text { Malformaciones vasculares } \\
\text { (malformaciones arteriales, } \\
\text { aneurismas, fístulas AV, } \\
\text { capilares, venosas, linfáticas } \\
\text { y linfangiomas) } \\
\text { Cefalea retroorbitaria, } \\
\text { soplo intracraneal y a veces } \\
\text { diplopia }\end{array}$ & $\begin{array}{l}\text { Exoftalmia reductible } \\
\text { Thrill a la palpación } \\
\text { Soplo a auscultación } \\
\text { Dilatación vasos } \\
\text { conjuntivales } \\
\text { Hipertonia ocular } \\
\text { Parálisis del VI } \\
\text { o Ill (a veces) } \\
\text { Arteriografia }\end{array}$ & & $\begin{array}{l}\text { Neurorradiología } \\
\text { Intervencionista }\end{array}$ \\
\hline & & $\begin{array}{l}\text { T. vasculares propiamente dichos } \\
\text { (hemangioma cavernoso y } \\
\text { hemangiopericitoma) } \\
\text { Exoftalmia no pulsátil, no } \\
\text { doloroso, sin afectación } \\
\text { función ocular }\end{array}$ & & & Cirugía \\
\hline $\begin{array}{l}\text { Malfor- } \\
\text { maciones } \\
\text { craniofaciales }\end{array}$ & Unilateral & $\begin{array}{l}\text { Disostosis craneales y } \\
\text { craniofaciales con } \\
\text { sinostosis }\end{array}$ & & & \\
\hline
\end{tabular}

${ }^{1}$ La exoftalmia edematosa maligna, es una complicación excepcional después de una tiroidectomía o algunas veces después de un tratamiento con yodo. Es una exoftalmia mayor, muy inflamatoria con maloclusiones palpebrales y oftalmoplejía. El tratamiento debe iniciarse inmediatamente con corticoterapia endovenosa, radioterapia orbital y, eventualmente, descompresión orbital. 
pelvis y las vértebras. Las metástasis orbitarias de carcinoma de próstata son raras. Con todo, hay más de 55 casos referenciados en la literatura ${ }^{2}$. En una revisión sobre 28 pacientes con metástasis orbitarias, 15 de los cuales eran hombres, con una edad media de aparición de 58,7 años, encontraron mayoritariamente metástasis unilaterales (14 casos afectando la órbita izquierda) y sólo 2 bilaterales. Asimismo, en dicha revisión el tumor primario se distribuía de la siguiente manera: carcinoma de mama $(28,6 \%)$, neuroblastoma $(25 \%)$, carcinoma de pulmón $(21,4 \%)$, carcinoma de próstata $(10,7 \%)$, carcinoma gastrointestinal $(7,1 \%)$, carcinoma células renales y carcinoma tiroidal $(7,1 \%$ cada uno). Los signos más frecuentes eran: proptosis $(67,9 \%)$, disfunción de la motilidad $(57,1 \%)$ y masa $(50 \%)^{3}$.

Conviene resaltar un dato importante de la historia clínica: el hecho que había una extensión tumoral con un PSA normal. Algunos autores ya habían descrito que la evaluación del PSA libre, es menos útil en pacientes con cáncer de próstata sometidos a deprivación androgénica ${ }^{4}$. La ratio PSA libre/total parecería ser más adecuada para el seguimiento de estos enfermos. Habría dos tipos de patrones de respuesta al tratamiento con análogos de la de hormona liberadora de la hormona luteinizante (LH$\mathrm{RH})$ reflejados en la ratio de PSA libre/total: los que el tratamiento es exitoso, en los que hay un incremento de esta ratio y los que recaen, en los que hay una disminución de esta ratio ${ }^{5}$. Esto llevado en la práctica clínica obligaría a monitorizar la recidiva tumoral de los enfermos que toman tratamiento con análogos LH-RH con la ratio PSA libre/total, rechazando la PSA libre como marcador tumoral de recidiva.

\section{CORRESPONDENCIA:}

Quintí Foguet Boreu

C/ Girona s/n (Jardins de Can Cendra)

Anglès 17160. Girona

Tel. 972421498

e-mail: qfoguetb@comg.es

\section{Bibliografía}

1. Morax S, Hamedani M. Exophtalmie. Orientation diagnostique. Le revue du practicien 2000; 50: 1223-9.

2. Inagaki T, Ebisuno S, Miyai M, Nakamura J. A case of protatic cancer metastasing to the orbit. Int J Urol 1999; 6 (2): 114-5.

3. Gunalp I, Gunduz K. Metastatic orbital tumors. Jpn J Ophththalmol 1995; 39 (1): 65-70.

4. Berruti A, Diogliotti L, Fasolis G, Mosca A, Tarabuzzi R,
Torta M, et al. Changes in free and free-to-total prostate specific antigen after androgen deprivation or chemotherapy in patients with advanced prostate cancer. J Urol 1999 Jan; 161 (1): 176-81.

5. Stein A, Barak M, Mecz Y, Rubinov R, Lurie A. Serum free/total prostatic-specific antigen in prostate cancer in patients treated with LH-RH agonists. Eur Urol 1997; 32 (1): 64-8. 